1. A parasite was allowed to examine, but not to oviposit in, four host eggs, numbered 1-4. Tho parasite was removed, three clean eggs placed alternately with the others, numbered 5-7, and a new parasite introduced. She readily oviposited in Nos. 2, 3, 5 and 6 , and also in Nos. $I$ and 7 after some examination. No. 4 was examined but not stung.

2. A repetition of the above, using ten eggs, numbered 1-10. The parasite examined but was prevented from ovipositing in eggs numbered 1, 2, $3,4,7,8$ and 10 , and was then removed, a further ten eggs, numbered 11-20, being placed alternately with the others. Three new female parasites were added and they oviposited in Nos. 2, 3, 4, 5, 13, 14 and 19. One of them oviposited twice in No. 3 .

3. In another batch of ten eggs, three parasites oviposited in eggs numbered $1,2,3,4,8,9,10$, one of them doing so twice in No. 4. The three insects were removed and ten fresh eggs, numbered 11-20, arranged alternately with the others. Three new parasites which were then introduced oviposited in Nos. 1, 3, 4, 6, 7, 8, 12 and 19.

These experiments indicate that the behaviour observed by Dr. Salt and Miss Laing is by no means fixed. Superparasitism is common in eggs which permit more than one full-sized individual to develop in them, at least under experimental conditions. For example, in one case, out of 100 eggs of Agrotis ypsilon, 93 were parasitised by $T$. evanescens, and 187 parasites emerged; with regard to the Eri silk worm moth, Attacus ricini, more than twenty commonly issue from one egg.

C. B. Redman King.

Tea Research Institute of Ceylon, St. Coombs, Talawakelle, Ceylon. Nov. 19

${ }^{1}$ Nature, 135, 792, May 11 (1935).

\section{Preliminary Report on Respiratory Studies of Littorina irrorata}

THE necessity for taking into consideration an organism's previous physiological condition in interpreting its respiratory rate was revealed incidentally in a series of experiments originally designed to show the effects of temperature and salinity on the respiratory rate of the intertidal gastropod Littorina irrorata.

Snails were collected after known periods of submergence and exposure, placed in two-litre bottles containing filtered sea-water at the desired temperature, and their respiratory rates measured by a semi-micro Winkler method. The rates of respiration at $32^{\circ} \mathrm{C}$., following periods of submergence of 0,12 , 24,48 , and 225 hours, were, respectively, $0 \cdot 31,0 \cdot 27$, $0.179,0.189$ and 0.168 c.c. oxygen per gram per hour. It seems, therefore, that after 24 hours of submergence the respiratory rate is relatively constant. The effect of exposure, following prolonged submergence, is to increase the respiratory rate. However, after a period of 50 hours of exposure, the rate appears to be fairly constant.

The average rate of respiration of Littorina irrorata, collected at random with respect to submergence time, was found to be 0.31 c.c. oxygen per gram per hour. This result is based on seven experiments performed at $32^{\circ} \mathrm{C}$.

To determine the effect of temperature on respiration, experiments were conducted at temperatures ranging from $10^{\circ}$ to $40^{\circ} \mathrm{C}$. The maximum rate measured, namoly 0.507 c.c. oxygen per grum per hour, occurred at $35^{\circ} \mathrm{C}$. The rate decreases rapidly at lower temperatures, having a valuo of 0.136 e.c. oxygen per gram per hour at $20^{\circ} \mathrm{C}$., and of 0.058 c.c. oxygen per gram per hour at $10^{\circ} \mathrm{C}$. The rate of respiration also decreases rapidly at temperatures above $35^{\circ} \mathrm{C}$. until approximately $43^{\circ} \mathrm{C}$. is reached, at which point a lethal effect is approached. It is difficult to obtain reliable results at temperatures below $10^{\circ} \mathrm{C}$. and above $40^{\circ} \mathrm{C}$. because all the snails do not remain open.

In all of these experiments, two parallel detorminations were run simultaneously, each with 15 specimens possessing a mean fresh body weight of $0.5129 \mathrm{gm}$. (width range, $16 \cdot 0-17 \cdot 9 \mathrm{~mm}$.). Two determinations were adequate, since the variation in oxygen consumption from the average seldom exceeded $t$ per cent.

The results emphasise the necessity for considering the submergence and exposure factors in respiratory studies of intertidal gastropods.

Curtis L. Newcombe.

Charles k. Mirler.

Donald W. Chappell.

Chesapeake Biological Laboratory and

University of Maryland.

\section{Record of Gorgonorhynchus at Bermuda}

The new marine Nemertean reported by Dakin and Fordham ${ }^{1}$ from the coastal waters of New South Wales has been found under stones at low tide at Bermuda. The peculiarity of Gorgonorhynchus, distinguishing it from all other members of the group, is the branching proboscis.

While collecting at St. George's Island in April, 1932, I found a Lineid worm which when irritated shot out a number of thin white threads in place of the single normal proboscis. Another worm similar in external appearance was taken in 1933, but the proboscis had been lost. This year a number of specimens have been collected, and the presence of the dichotomously branched proboscis confirmed. The worms have been observed to swim with an undulatory movement suggestive of the genus Cerebratulus, and this relationship is further shown by the presence of a caudal appendage.

The occurrence of this animal in localities so remote from one another as New South Wales and Bermuda is an interesting problem in distribution.

\section{J. F. G. WheELER.}

\section{Bermuda Biological Station} for Research, Inc.,

St. George's West, Bermuda.

${ }^{1}$ Dakin, W. J., and Fordham, M. G. C., Natreke, 128, 796 (1931).

\section{Physiological Races of Lucilia sericata, Mg.}

RATCLIFFE ${ }^{1}$ has recently suggested that there may possibly be two physiological races of $L$. sericata, as the length of the pupal period of this insect at 32 : in Scotland is 5.4 days while in France at the same temperature it is 8 days. This latter figure is quoted from a paper by Davies ${ }^{2}$ who, in turn, is only guoting the work of Cousin ${ }^{3}$ in France. Unfortunately, the figure given by Davies is inaccurate and should be 4.9 days, not 8 days. I have found ${ }^{4}$ that humidity 